\title{
Sentinel Site Development of a Major Salt Marsh System in the Mid-Atlantic Region (USA)
}

\author{
Michael J. Kennish ${ }^{*}$, Andrea Spahn², Gregg P. Sakowicz ${ }^{2}$ \\ ${ }^{1}$ Institute of Marine and Coastal Sciences, Rutgers University, New Brunswick, USA \\ 2Jacques Cousteau National Estuarine Research Reserve, Tuckerton, USA \\ Email: ${ }^{*}$ kennish@marine.rutgers.edu
}

Received 10 December 2013; revised 10 January 2014; accepted 17 January 2014

Copyright (C) 2014 by authors and Scientific Research Publishing Inc.

This work is licensed under the Creative Commons Attribution International License (CC BY). http://creativecommons.org/licenses/by/4.0/

\section{Open Access}

\section{Abstract}

The Tuckerton Peninsula, a large expanse ( 2000 ha) of highly inundated Spartina alterniflora salt marsh habitat, forms one of the most extensive coastal wetland systems in New Jersey (USA). It is projected to be among the first salt marsh systems in New Jersey to be lost by rising sea level driven by climate change. The changes that occur in the demographic, ecologic, and ecogeomorphic characteristics of the salt marsh habitat at this location will be vital to understanding future habitat change in coastal wetlands in the Mid-Atlantic region. As a consequence, the Tuckerton Peninsula salt marsh system is designated as a sentinel site of the Jacques Cousteau National Estuarine Research Reserve (JCNERR) for the detection, monitoring, and assessment of climate change effects, most notably sea-level rise and inundation. Development of the Tuckerton Peninsula as a sentinel site requires a high accuracy local geodetic control network to connect existing water quality monitoring stations, vegetation transects and monitoring surface elevation tables, ground water wells, and digital elevation models on the same vertical datum. The integration of these monitoring infrastructure components is crucial to effective operation of the sentinel site. It will enable the collection of essential data to assess rates of marsh migration and upland transgression, as well as delineate key natural and anthropogenic drivers influencing habitat condition and change. The JCNERR sentinel site designation supports the National Oceanic and Atmospheric Administration's long-term goal of assessing coastal vulnerability in the USA to climate change and generating data useful for forging climate adaptation and mitigation initiatives for coastal communities. Habitat and vertical control data collected at this sentinel site will be made available to decision makers across the nation and will enable them to determine how the loss of critical salt marsh habitat will affect coastal communities, their adaptation to future habitat loss, and their development of mitigation plans to address impacts and enhance resiliency.

\footnotetext{
"Corresponding author.
} 


\section{Keywords}

\section{Tuckerton Peninsula Salt Marsh System; Vulnerability; Climate Change Effects; Monitoring; Assessment; Coastal Management}

\section{Introduction}

The Tuckerton Peninsula is the designated sentinel site of the Jacques Cousteau National Estuarine Research Reserve (JCNERR) for the detection and monitoring of climate change effects, most notably sea-level rise and inundation. According to the National Estuarine Research Reserve System (NERRS) [1], a sentinel site is defined as a discrete location in coastal and marine environments that has the operational capacity for intensive study and sustained observations to detect and understand physical and biological changes in the ecosystem it represents. Such is the case for the 2000-ha Tuckerton Peninsula Spartina salt marsh system. Broad expanses of the marsh surface are susceptible to inundation and submergence. Reduction in marsh habitat area has accelerated due to extreme weather events, storm surge, sea-level rise, perimeter shoreline erosion, and coastal submergence. It is ongoing sea-level rise, inundation, and shoreline erosion that provide the focus of sentinel site monitoring efforts in the Tuckerton Peninsula.

Climate forecasting models indicate that there will be increasing frequency and severity of damaging storms, storm surges, and flooding of coastal environments as global temperatures rise during the 21st century [2] [3]. Coastal inundation and the loss of coastal wetlands will leave local coastal communities and infrastructure highly vulnerable to storms, flooding, and other extreme events. With current sea-level rise amounting to 3 - 4 $\mathrm{mm} \cdot \mathrm{yr}^{-1}$ in New Jersey [4] [5], marsh surfaces must continue to vertically aggrade to keep pace with the increasing water levels. Miller et al. [5] note that global sea level may rise $80-\mathrm{cm}$ by 2100 . In addition, the New Jersey coastline is sinking due to compaction and isostatic adjustment, which will add another 9 to $18 \mathrm{~cm}$ of sea surface elevation by 2100. A relative sea-level rise of 1 to $1.2 \mathrm{~m}$ by 2100 , which is projected by some investigators for New Jersey, would result in the loss of about 3\% of the land area in the state and $30 \%$ of the coastal marshlands. This will have grave implications for the New Jersey's coastal infrastructure. In addition, flooding will be more common. A "100-year" storm causes a surge of $2.5 \mathrm{~m}$. By 2100 , such surges would recur annually, flooding access to bridges, tunnels, and some upland areas.

JCNERR has been conducting extensive biomonitoring of the emergent salt marsh communities along nine sampling transects in the Tuckerton Peninsula since 2011, and these data will add significantly to the database of the NERRS sentinel site network. By collecting and analyzing data consistently through time on emergent vegetation in the peninsula, habitat trends and baseline data useful for characterizing spatio-temporal structural and marsh composition changes are being established that will be useful for effective coastal zone management. The changes observed in the demographic and ecological characteristics of the emergent Spartina salt marsh habitat will also be vital to understanding the dynamics of future salt marsh habitat change in other coastal wetlands of New Jersey and the mid-Atlantic region subjected to rising sea level and inundation. It will also serve as a local reference platform for ecological assessment of other salt marsh systems in the NERRS program. Integrating habitat characterization of the Tuckerton Peninsula salt marsh platform with vertical control infrastructure proposed in this work will provide a comprehensive approach to enable the JCNERR to function effectively as a sentinel site for climate change research and monitoring.

\section{Management Issues}

Management plans are being formulated by the JCNERR to advise coastal communities in New Jersey that will ensure effective adaptation strategies for future loss of salt marsh systems such as the Tuckerton Peninsula. Time-series data collected on salt marsh systems along latitudinal gradients, (e.g., a network of NERRS sites) will provide key indicators necessary for effectively assessing drivers of environmental change and for delineating the condition of the emergent plant communities at a national network of monitoring sites.

The establishment of the JCNERR sentinel site supports the National Oceanic and Atmospheric Administration's long-term goal of assessing coastal vulnerability to climate change and the generation of data useful for 
forging climate adaptation and mitigation initiatives for coastal communities. Habitat and vertical control data collected at the JCNERR sentinel site will be made available to decision makers across New Jersey and will enable them to determine how the loss of critical salt marsh habitat will affect their coastal communities, their adaptation to future habitat loss, and their development of mitigation plans to address impacts. All of these data will be vital to long-term resiliency in the state, particularly in the aftermath of the sweeping coastal destruction from Hurricane Sandy.

Empirical research and monitoring at the Tuckerton Peninsula will also be useful for management applications such as the calibration of a Sea-Level Affecting Marshes Model (SLAMM) to project future salt marsh responses and vulnerability to climate change, as well as to inform municipal and county governments of the economic benefits of monitoring coastal wetlands for future assessment and for developing adaptation measures for responding to the loss of this salt marsh system. These sentinel site activities, therefore, will provide valuable technical and management information that will be important for stakeholders in assessing climate change impacts and adaptation programs in New Jersey.

\section{Adaptation Planning, Coastal Training, and Outreach}

NERRS sentinel site plans specify strategies for including target audiences and organizations in the development, use, and dissemination of sentinel site data and other derived products. JCNERR's Education and Coastal Training Programs will play an important role in the dissemination of the sentinel site data to partners, stakeholders, and other entities. Communication and outreach of sentinel site data and other information to appropriate audiences or stakeholders are necessary elements to effectively implement the sentinel site plan.

JCNERR will develop a strategy for translating findings into an initial framework for adaptation planning. A full range of federal and non-federal partners will have access to research and monitoring data collected at the JCNERR sentinel site, including the US Fish and Wildlife Service, N. J. Division of Fish and Wildlife, N. J. Coastal Zone Management Program, municipal governments (Little Egg Harbor, Stafford, and Toms River townships), county government (Ocean County Planning), and non-governmental organizations (American Littoral Society and Pinelands Preservation Alliance). It is particularly important to work closely with the N. J. Coastal Zone Management program and Ocean County Planning Department to integrate sentinel site results into relevant state and county government operations. These results will also be significant in developing an effective adaptation plan to address long-term climate change impacts in Ocean County and elsewhere.

Higher tides and more frequent flooding incidents are becoming more regular in coastal New Jersey. Due to the earth's changing climate, these types of events are expected to be more frequent and more intense [2]. Planning for future impacts on wetlands systems and other coastal habitats through community education and outreach will enable our communities to be prepared and more resilient. The JCNERR website "Getting to Resilience" will be incorporated into the sentinel site plan. This website is an online self-assessment developed to assist coastal communities in reducing vulnerability and increase preparedness by linking planning, mitigation, and adaptation to climate change. The assessment process will increase a community's understanding of where future vulnerabilities should be addressed through hazard mitigation planning, such as at the Tuckerton Peninsula sentinel site. Developed to be used in connection with another website, NJFloodMapper.org, "Getting to Resilience" is the next step in the planning of coastal communities for the risks associated with climate change and sea-level rise. Together, these websites will help New Jersey's coastal communities visualize their future risk and plan for that risk using their existing municipal planning tools. Key municipal officials and staff will include Land Use Planners, Hazard Mitigation Planners, Floodplain Managers, Emergency Managers, Stormwater Managers, Natural Resource Planners, Municipal Engineers, Municipal Leaders, Zoning and Permitting Officials, and Public Works Officials.

In addition to the website use noted above, education and outreach workshops will be held to present stakeholders and partners with the sentinel site monitoring and assessment data, their significance to the coastal communities of Ocean County, applications to other coastal areas in the mid-Atlantic region and elsewhere, and relevance to the Climate Change Office of the National Oceanic and Atmospheric Administration. This component will thus serve as an interactive education and coastal training initiative. In addition, the outreach platform will also empower the public with the tools needed to begin effective adaptation planning to prepare for the land and habitat changes that will take place with the loss of the Tuckerton Peninsula salt marsh system and other critical coastal habitat. 


\section{Program Capacity}

The JCNERR has the capacity to attract and/or leverage partnerships, including areas where the sentinel sites can support and connect to other regional observing networks. In addition, the JCNERR has the technical staffing capacity to conduct and sustain the sentinel site monitoring program at the Tuckerton Peninsula salt marsh system as demonstrated by the biomonitoring initiative completed in 2011 [6] and ongoing biomonitoring of the Tuckerton Peninsula salt marsh system in 2013.

\section{Sentinel Site Monitoring Infrastructure}

An important NERRS protocol for sentinel sites requires establishing high accuracy local geodetic control networks to connect existing System-wide Monitoring Program (SWMP) stations, vegetation transects and monitoring, surface elevation tables, ground water wells, and digital elevation models on the same vertical datum (Figure 1) [1]. The integration of these monitoring infrastructure components is crucial to effective operation of NERRS sentinel sites. It will enable the collection of critical data to assess rates of marsh migration and upland transgression, as well as delineate the key drivers influencing habitat condition and change.

\subsection{JCNERR SWMP Monitoring Stations}

Four SWMP water quality monitoring stations have operated in the JCNERR since 1996. These SWMP stations occur along a salinity gradient of the Mullica River-Great Bay Estuary at Lower Bank (39 $\left.{ }^{\circ} 35.618^{\prime} \mathrm{N}, 74^{\circ} 33.091^{\prime} \mathrm{W}\right)$, Chestnut Neck (39 $\left.32.872^{\prime} \mathrm{N}, 74^{\circ} 27.676^{\prime} \mathrm{W}\right)$, Buoy $139\left(39^{\circ} 29.883^{\prime} \mathrm{N}, 74^{\circ} 22.8733^{\prime} \mathrm{W}\right)$ and Buoy $126\left(39^{\circ} 30.478^{\prime} \mathrm{N}\right.$, $74^{\circ} 20.308^{\prime} \mathrm{W}$ ) in close proximity to the Tuckerton Peninsula salt marsh system (Figure 2). Data collected at these SWMP stations are important for correlation with spatial and temporal changes in salt marsh habitat and wetland elevation at the sentinel site.

\subsection{Vegetation Transects and Monitoring}

In response to relative sea-level rise, tidal salt marshes will undergo both structural and functional changes manifested by shifts in species composition, distribution, and abundance of marsh vegetation. Rising sea level and greater tidal inundation, for example, will cause a shift in the interface between low marsh (dominated by Spar-

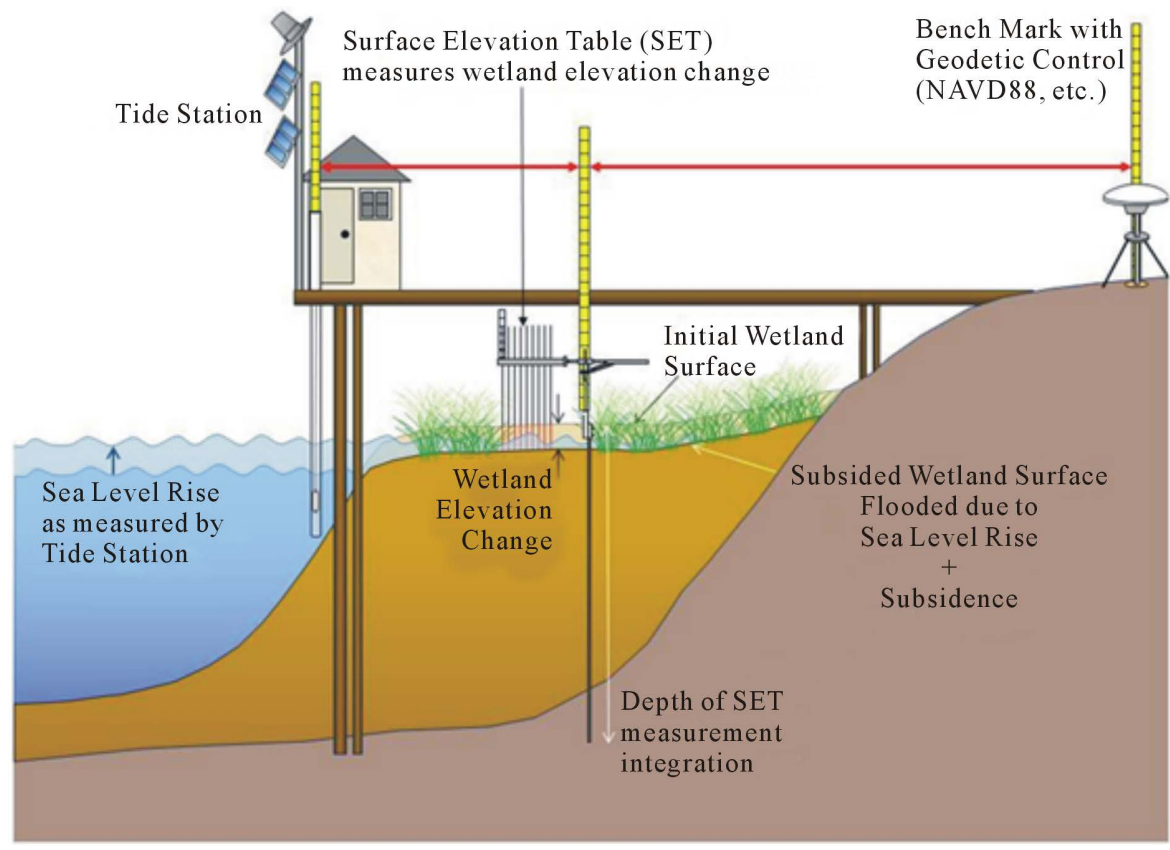

Figure 1. Sentinel Sites Geospatial Infrastructure Conceptual Model of the National Estuarine Research Reserve System [1]. 

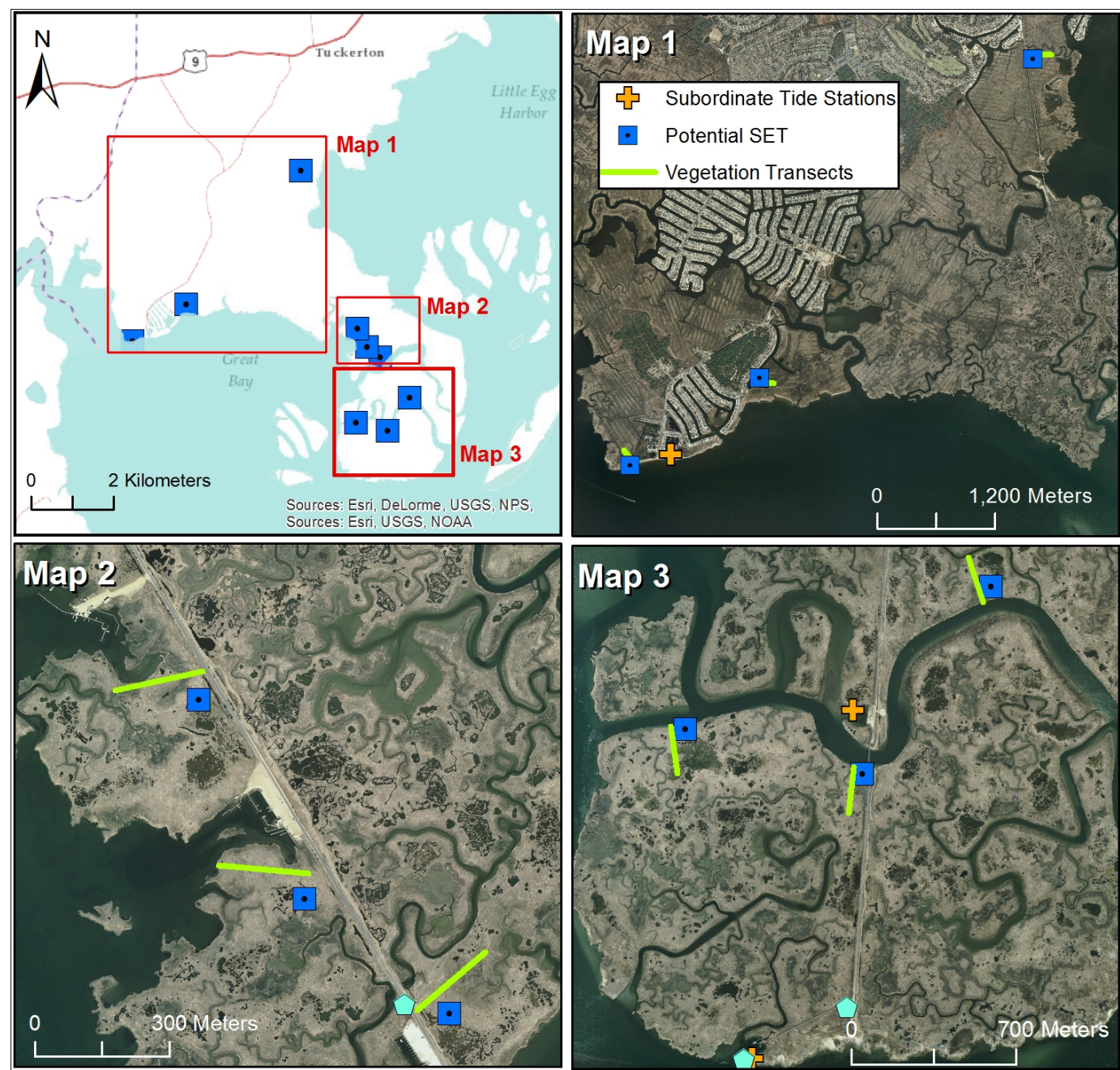

Figure 2. Proposed surface elevation table locations in the Tuckerton Peninsula salt marsh system. Note location adjacent to established vegetation monitoring transects of the Jacques Cousteau National Estuarine Research Reserve.

tina alterniflora) and high marsh (domintated by Spartina patens) habitat that can be tracked by conducting SWMP vegetation monitoring using protocols of the NERRS vegetation monitoring plan [7]. Such shifts in marsh vegetation composition can be linked to land cover extent evident in habitat mapping for a more complete characterization of the reserve.

Comprehensive emergent vegetation monitoring of the Tuckerton Peninsula salt marsh system in the JCNERR was conducted in 2011 and 2013 [6]. Nine permanent transect lines (Figure 2) have been established in three salt marsh segments (north, central, and south): Transects 1 - 3 (north segment), Transects 4 - 6 (central segment), and Transects 7 - 9 (south segment). Monthly quadrat sampling during peak salt marsh biomass periods (June - September) was conducted at each of 90 plots along these 9 transects. This field sampling design will be used in all future emergent vegetation monitoring of the system that will be tied to the National Spatial Reference System (NSRS).

\subsection{Surface Elevation Tables (SETs)}

There are currently no SETs deployed within the Tuckerton Peninsula salt marsh system. The JCNERR plans to deploy nine SETs in the peninsula adjacent to each of the nine established vegetation monitoring transects (Figure 2). These SETs are needed to effectively measure the salt marsh elevation change relative to local sea level. When the funding base is in place for the SETs, standardized protocols will be followed for connecting 
SET benchmarks to the NSRS using system geodetic surveying techniques.

\subsection{Surface Elevation Models}

A digital elevation model will be generated using Real Time Kinematic GPS (RTK) at 1-m intervals in the three salt marsh segments. These measurements will be repeated regularly in future years to document broad surface elevation change over consistent temporal intervals and to augment fine-scale surface elevation change data obtained using SETs located adjacent to the nine transects in the north, central, and south segments of the marsh.

\subsection{LiDAR Data}

LiDAR data has been acquired in the mid-Atlantic and is available for the Tuckerton Peninsula salt marsh system and contiguous areas of the Mullica River Basin. This data will also be used in development of surface elevation models. Additional LiDAR data acquisition is also planned across the same region over the next year which can be used for the same purpose.

\subsection{Sea Level}

Tidal bench marks will be tied to the National Spatial Reference System (NSRS) by the JCNERR staff working in conjunction with state geodetic crews. The vertical control infrastructure must be tied to local tidal datums. The National Water Level Observation Network (NWLON) is a network of tide stations that provides information on local tidal datums and sea-level trends. JCNERR is in a NWLON gap (Figure 3). Tidal infrastructure will need to be installed as part of the vertical control network to measure relative sea level.

The closest NWLON Station to the JCNERR is in Atlantic City, New Jersey. The Atlantic City tide station was established in 1911, and the current installation began in 1991. This station has recorded approximately 100 years of sea-level data (Figure 4).

There are three historic tide stations that have been taken offline near the Tuckerton Peninsula. Two of the three stations, Little Sheepshead Creek and Graveling Point, have tidal benchmarks that have been recovered but not tied to the North American Vertical Datum (NAVD) of 1988 (NAVD88). Efforts should be made by JCNERR staff and state geodetic crews to tie the tidal benchmarks to the National Spatial Reference System. Table 1 identifies the NWLON and historic tide stations with calculated local tidal datums. The JCNERR plans

Table 1. Tide Stations closest to JCNERR Tuckerton Peninsula and the relationship of the 1973-2011 tidal epoch water levels to Mean Lower Low Water [10].

\begin{tabular}{|c|c|c|c|c|}
\hline Station Name & Atlantic City & Little Sheepshead Creek & Great Bay, Tuckerton & Graveling Point \\
\hline Station ID & 8534720 & 8534287 & 8534319 & 8534244 \\
\hline Station Type & Harmonic & Subordinate Station & Subordinate Station & Subordinate Station \\
\hline Length of Series & 19 years & 9 months & N/A & 1 Year \\
\hline Date Established & Aug. 15, 1911 & Sept. 30, 1976 & Sept. 13, 1976 & Aug. 3, 1977 \\
\hline Date Removed & N/A & Jan. 11, 1978 & Jan. 11, 1978 & Dec. 5, 1978 \\
\hline Highest Observed Water Level & $\begin{array}{c}2.739 \mathrm{~m} \\
(12 / 11 / 1992)\end{array}$ & N/A & N/A & $\begin{array}{c}1.934 \mathrm{~m} \\
(10 / 14 / 1977)\end{array}$ \\
\hline Mean Higher High Water (MHHW) & $1.403 \mathrm{~m}$ & $1.094 \mathrm{~m}$ & N/A & $1.117 \mathrm{~m}$ \\
\hline Mean High Water (MHW) & $1.276 \mathrm{~m}$ & $0.984 \mathrm{~m}$ & N/A & $1.009 \mathrm{~m}$ \\
\hline $\begin{array}{c}\text { North American Vertical Datum of } \\
1988 \text { (NAVD88) }\end{array}$ & $0.797 \mathrm{~m}$ & $\mathrm{~N} / \mathrm{A}$ & $\mathrm{N} / \mathrm{A}$ & $\mathrm{N} / \mathrm{A}$ \\
\hline Mean Tide Level (MTL) & $0.663 \mathrm{~m}$ & $0.512 \mathrm{~m}$ & N/A & $0.524 \mathrm{~m}$ \\
\hline Mean Sea Level (MSL) & $0.675 \mathrm{~m}$ & $0.503 \mathrm{~m}$ & N/A & $0.516 \mathrm{~m}$ \\
\hline Mean Low Water (MLW) & $0.051 \mathrm{~m}$ & $0.039 \mathrm{~m}$ & N/A & $0.039 \mathrm{~m}$ \\
\hline Mean Lower Low Water (MLLW) & $0 \mathrm{~m}$ & $0 \mathrm{~m}$ & N/A & $0 \mathrm{~m}$ \\
\hline Lowest Observed Water Level & $\begin{array}{c}-1.362 \mathrm{~m} \\
(01 / 10 / 1978)\end{array}$ & N/A & N/A & $\begin{array}{c}-0.733 \mathrm{~m} \\
(12 / 10 / 1977)\end{array}$ \\
\hline
\end{tabular}




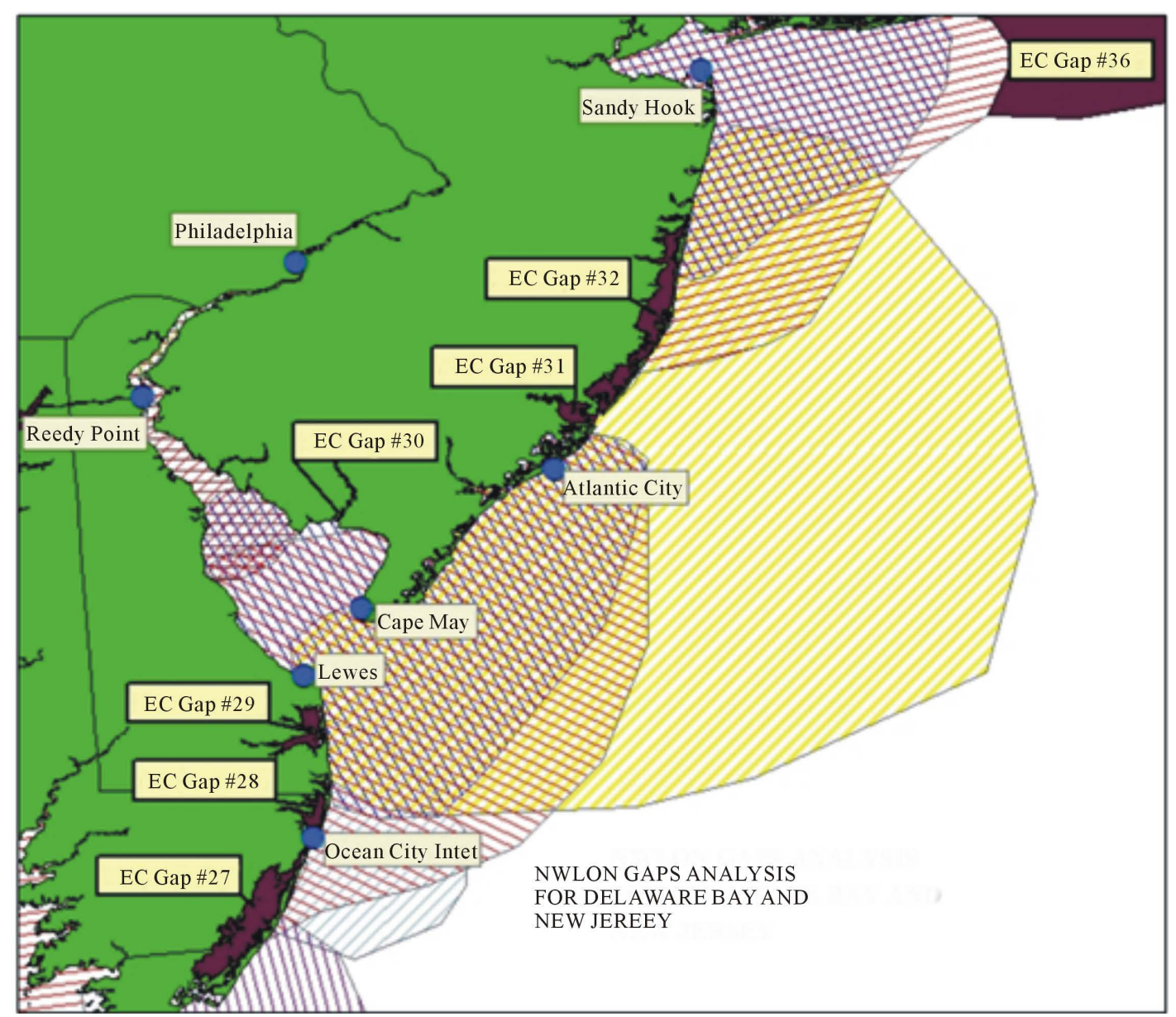

Figure 3. NWLON gap analysis for Delaware and New Jersey. JCNERR is in EC Gap \#31 [8].

to install a new tide gauge station in Little Sheepshead Creek.

Salt marshes in New Jersey are particularly vulnerable to rising sea level and inundation. This is compounded by coastal subsidence that is actively occurring in New Jersey, which has accounted for a relative rise in sea level of $\sim 20 \mathrm{~cm}$ over the past century. Current sediment accretion rates $\left(0.18\right.$ to $\left.0.30 \mathrm{~cm} \cdot \mathrm{yr}^{-1}\right)$ in proximity to the Tuckerton Peninsula salt marsh system barely keep pace with local rates of relative sea-level rise $(0.17 \pm 0.07$ $\mathrm{cm} \cdot \mathrm{yr}^{-1}$ ) [11]. The rate of loss of salt marsh habitat along the eastern and southern shorelines of the south segment amounted to $1.6 \mathrm{~m} \cdot \mathrm{yr}^{-1}$ between 1995 and 2008. Losses may accelerate in the future due to the predicted increase in the rate of sea-level rise of $1-2 \mathrm{~mm} \cdot \mathrm{yr}^{-1}$ over the next 100 years [2]. Tidal salt marsh distribution, production, and biodiversity are particularly sensitive to environmental variations, including inundation periods associated with sea-level rise. Due to the importance of plant-mediated vertical sediment accretion within salt marshes, any change in vegetative production rates associated with climate induced increase in sea-level rise could significantly impact future stability of salt marsh ecosystems [12].

\subsection{Geodetic Benchmarks}

Figure 5 shows the location of vertical control benchmarks and other infrastructure elements for the proposed JCNERR sentinel site. Three are located in the Tuckerton Peninsula salt marsh platform, one in the central segment and two in the south segment. The fourth benchmark is located on the southern end of Long Beach Island. All of the benchmarks have been tied to NAVD88. These four benchmarks provide sufficient framework to tie planned vertical control infrastructure to the NSRS. In the future there will be a need for more vertical control benchmarks in the north segment of the Tuckerton Peninsula salt marsh system and potentially in the south segment. Table 2 provides coordinates and elevations of the four benchmarks. 

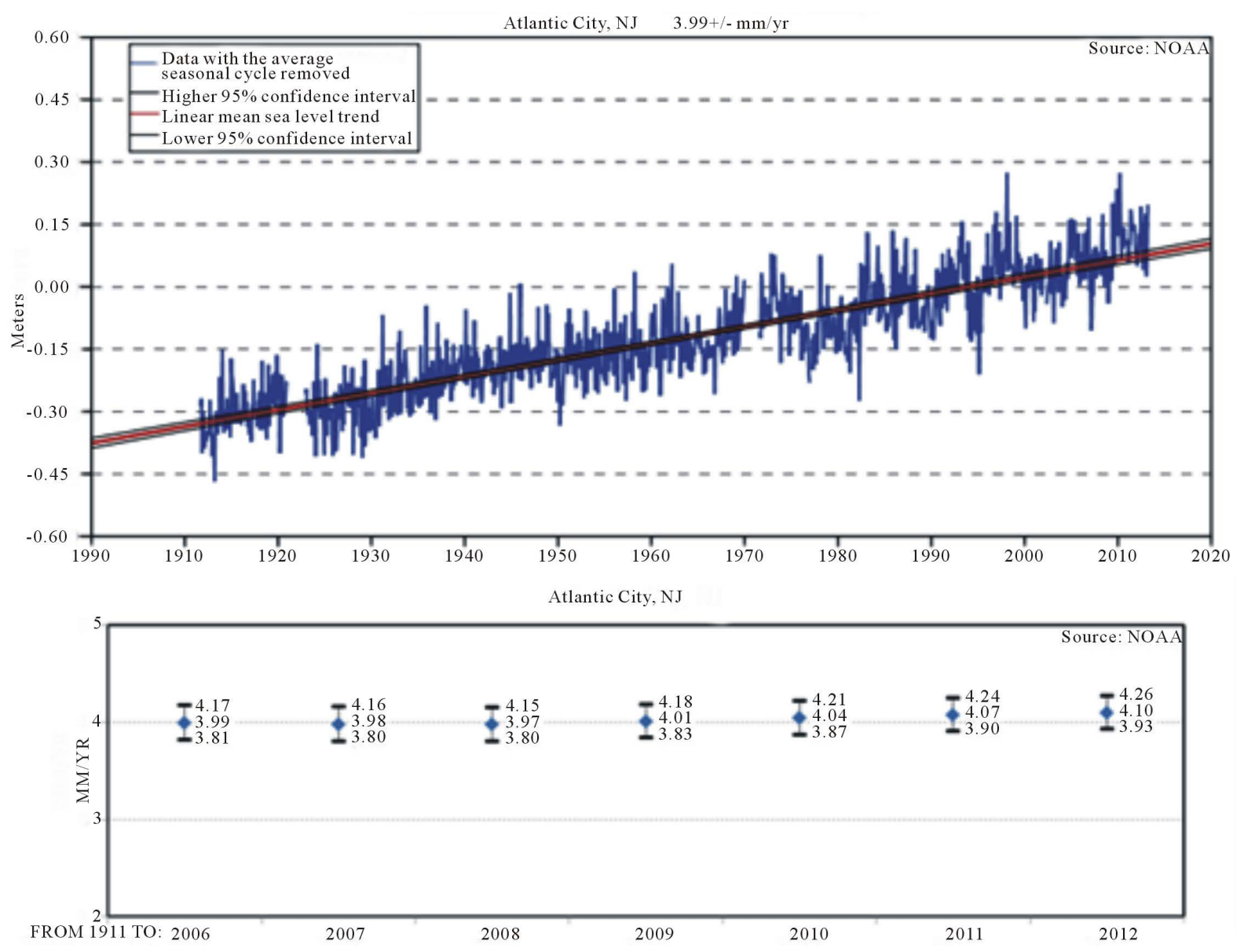

Figure 4. Sea-level trends in Atlantic City, New Jersey. The mean sea-level trend is $3.99 \mathrm{~mm} / \mathrm{yr}$ with a $95 \%$ confidence interval of $+/-0.18 \mathrm{~mm} / \mathrm{yr}$ based on monthly mean sea-level data from 1911 to 2006 [9].

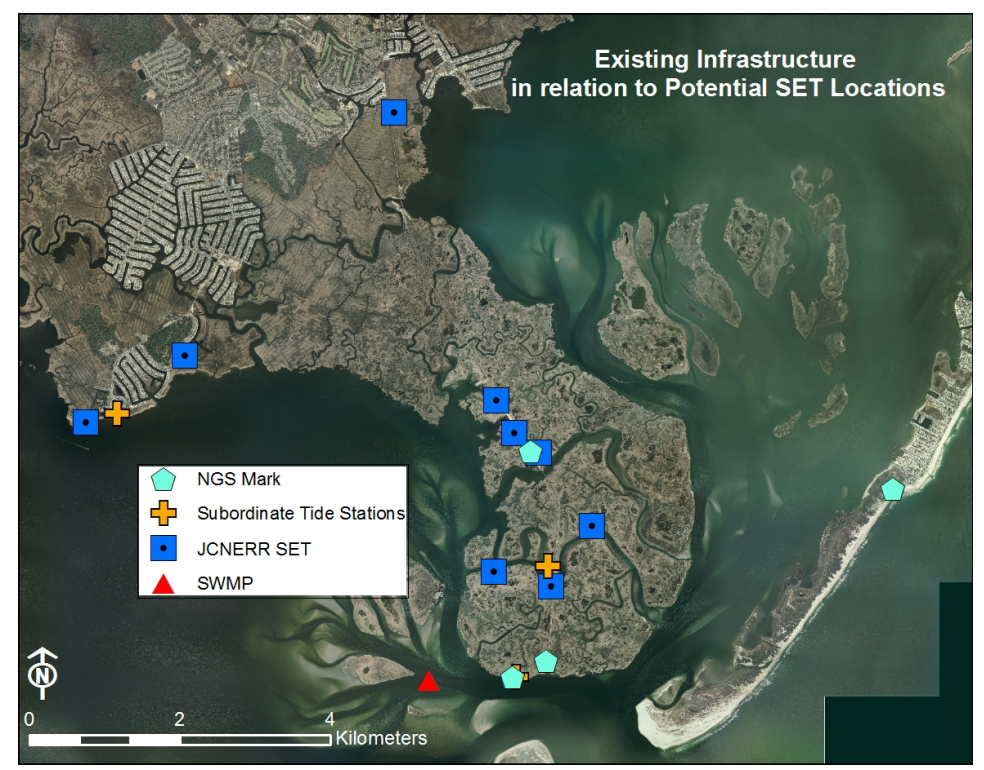

Figure 5. Vertical control benchmarks, subordinate tide stations, proposed SET locations, and the SWMP Buoy 126 monitoring site in proximity to the Tuckerton Peninsula sentinel site of the JCNERR. 


\subsection{Continuously Operating GPS Reference Stations (CORS)}

Data supporting three-dimensional positioning for the Global Navigation Satellite System (GNSS) derives from the CORS system, which is a key element of the geodetic control network. Managed by the National Geodetic Survey of the National Ocean Service, CORS is critical for measuring accurate land elevations. CORS enables high accuracy positions to be obtained through post-processing of GPS data. Figure 6 shows the CORS locations within proximity of the JCNERR sentinel site. Some are located within $50 \mathrm{~km}$ of the JCNERR boundaries (Table 3), but permanent CORS within closer proximity to the Tuckerton Peninsula salt marsh platform would increase effectiveness.

\section{Data Archiving, Synthesis, and Translation}

All JCNERR sentinel site monitoring data will be stored on the dellserver at the Rutgers University Marine Field Station (RUMFS) in Tuckerton and backed up on the main server at the Institute of Marine and Coastal Sciences

Table 2. Locations and elevations of current vertical control benchmarks for the JCNERR sentinel site plan. Northing and Easting locations are shown in NAD 83 (2011), UTM Zone 18N. Elevations are NAVD88, Geoid12A [13].

\begin{tabular}{ccccccccc}
\hline Designation & PID & $\begin{array}{c}\text { Vertical } \\
\text { Order }\end{array}$ & Latitude & Longitude & $\begin{array}{c}\text { Ellips. } \\
\text { Height (m) }\end{array}$ & $\begin{array}{c}\text { Northing } \\
(\mathbf{m})\end{array}$ & $\begin{array}{c}\text { Easting (m) } \\
\text { (mAVD88 } \\
\text { (m) }\end{array}$ \\
\hline FWS Holgate & DE9211 & $1^{\text {st }}-$ class I & 39.530823 & -74.266531 & -32.247 & 4375942.127 & 563035.39 & 1.678 \\
M 55 & JU0235 & $1^{\text {st }}-$ class II & 39.535447 & 74.322547 & -33.135 & 4376417.548 & 558217.377 & 0.666 \\
Shooting & JU2727 & $1^{\text {st }}$ - class II & 39.510296 & -74.32031 & -33.362 & 4373627.638 & 558430.719 & 0.395 \\
853 4319 D & N/A & N/A & 39.50831 & -74.325412 & -32.722 & 4373403.979 & 557993.780 & 1.189 \\
\hline
\end{tabular}

Table 3. CORS stations located in proximity to the Tuckerton Peninsula [14].

\begin{tabular}{cccccc}
\hline Station Name & Station ID & PID & Approximate Distance (km) & Sampling Rate (sec) & Operational Status \\
\hline R. Stockton College & NJGT & DL1896 & 19.10 & $1 \mathrm{sec}$ & Operational \\
NJ OC & NJOC & DI1077 & 46.64 & $1 \mathrm{sec}$ & $1 \mathrm{sec}$ \\
Operational & & $1 \mathrm{sec}$ & Operational \\
Niddle Township & NJCM & DI3828 & Operational & Opec \\
\hline
\end{tabular}

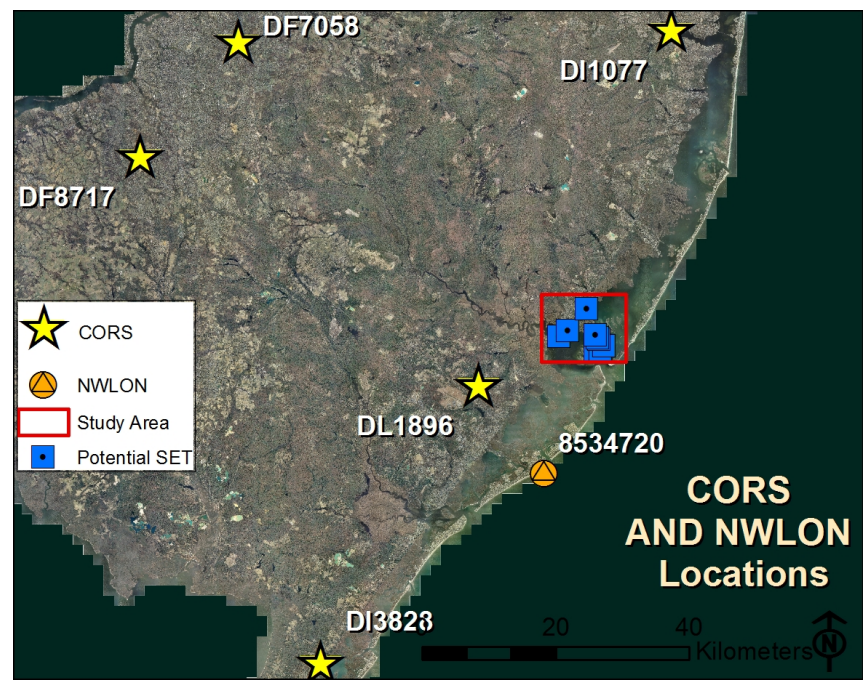

Figure 6. JCNERR sentinel site showing proposed SETs, CORS locations (identified by Permanent Identifier-PID), and NWLON Tide Station in the region. 
(IMCS) at Rutgers University in New Brunswick. IMCS and the Center for Remote Sensing and Spatial Analysis (CRSSA) will also serve as the centers for data analysis, storage, and management. RUMFS, IMCS, and CRSSA have the computing capability and data management tools necessary to ensure that data storage and data analyses are well supported. The collected data will also be submitted quarterly to the NERRS Centralized Data Management Office for archiving. Emergent vegetation monitoring data, data associated with local geodetic networks and associated elevations, as well as other vertical control data acquisition will be reviewed by staff personnel and periodically synthesized to meet the management needs of the JCNERR and NERRS programs. In addition, the data will also be evaluated annually for their utility for end-users.

\section{Acknowledgements}

Support for this work by the National Estuarine Research Reserve Program, Jacques Cousteau National Estuarine Research Reserve (JCNERR), and the Institute of Marine and Coastal Sciences at Rutgers University is gratefully acknowledged. We thank Richard A. Lutz, Director of the Institute of Marine and Coastal Sciences at Rutgers University, Michael De Luca, Manager of the JCNERR, Lisa Auermuller, Coastal Training Program Coordinator of the JCNERR, Melanie Reding, Education Coordinator of the JCNERR, and the other staff members of the JCNERR Program. This is Contribution Number 5214 of the Institute of Marine and Coastal Sciences, Rutgers University.

\section{References}

[1] National Estuarine Research Reserve System (2012) Sentinel Sites Program Guidance for Climate Change Impacts. Technical Report, NOAA National Estuarine Research Reserve Program, Office of Ocean and Coastal Resource Management, Silver Spring, Maryland.

[2] Intergovernmental Panel on Climate Change (IPCC) (2007) IPCC Fourth Assessment Report: Climate Change 2007. Cambridge University Press, Cambridge.

[3] Robinson, D. (2011) Weather or Not? New Jersey Climate Change. http://envirostewards.rutgers.edu/Lecture\%20Resource\%20Pages/2011LectureNotes/Robinson\%20EnvirStewards_Apr 11.pdf

[4] Psuty, N.P. and Ofiara, D.D. (2004) Coastal Hazard Management: Lessons and Future Directions from New Jersey. Rutgers University Press, New Brunswick.

[5] Miller, K.G., Sugarman, P.J., Browning, J.V., Horton, B.P., Stanley, A., Kahn, A., Uptegrove, J. and Aucott, M. (2009) Sea-Level Rise in New Jersey over the Past 5000 Years: Implications to Anthropogenic Changes. Global and Planetary Change, 66, 10-18. http://dx.doi.org/10.1016/j.gloplacha.2008.03.008

[6] Kennish, M.J., Fertig, B.M. and Petruzzelli, G. (2012) Emergent Vegetation: NERR SWMP Tier 2 Salt Marsh Monitoring in the Jacques Cousteau National Estuarine Research Reserve. Technical Report to the National Estuarine Research Reserve Program (NOAA), Institute of Marine and Coastal Sciences, Rutgers University, New Brunswick, New Jersey. 22 pp. plus appendices.

[7] National Estuarine Research Reserve System (2013) NERRS SWMP Vegetation Monitoring Protocol Long-Term Monitoring of Estuarine Vegetation Communities. Technical Report, NOAA National Estuarine Research Reserve Program, Office of Ocean and Coastal Resource Management, Silver Spring, Maryland.

[8] NOAA Technical Memorandum NOS CO-OPS 0048: A Network Gaps Analysis for the National Water Level Observation Network. March 2008.

[9] NOAA CO-OPS Sea Levels Online. http://tidesandcurrents.noaa.gov/

[10] NOAA Tides and Currents. http://tidesandcurrents.noaa.gov/

[11] Velinsky, D., Enache, M., Charles, D., Sommerfield, C. and Belton, T. (2011) Nutrient and Ecological Histories in Barnegat Bay, New Jersey. Technical Report, Academy of Natural Sciences, Philadelphia, Pennsylvania.

[12] Kirwan, M.L., Guntenspergen, G.R. and Morris, J.T. (2009) Latitudinal Trends in Spartina alterniflora Productivity and the Response of Coastal Marshes to Global Chance. Global Change Biology, 15, 1982-1989. http://dx.doi.org/10.1111/j.1365-2486.2008.01834.x

[13] National Geodetic Survey. www.ngs.noaa.gov/NGSDataExplorer

[14] National Geodetic Survey Website. http://www.ngs.noaa.gov/CORS_Map/ 